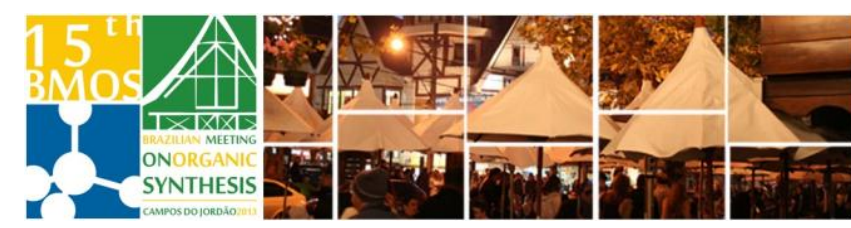

\title{
Synthesis of quinolines derivatives by multicomponent reaction promoted by $\mathrm{NbCl}_{5}$
}

\section{Giovanny Carvalho dos Santos, ${ }^{*}$ Aloisio de Andrade Bartolomeu and Luiz Carlos da Silva-Filho.}

\author{
Laboratory of Organic Synthesis and Catalysis, POSMAT, UNESP-Bauru, Av. Eng. Luiz Edmundo Carrijo \\ Coube, 14-01, CEP 17033-360, Vargem Limpa, Bauru, S.P.
}

*giovannycarvalho@fc.unesp.br

Keywords: Niobium Pentachloride, Multicomponent Reactions, Quinolines.

\section{INTRODUCTION}

The quinolines derivatives can be synthetized by Multicomponent Reaction (MCR) using niobium pentachloride that act as Lewis Acid provides an easy access to the preparation. The MCRs are defined as a process in which three or more reagents are combined in the same reaction "pot", generating the products with good structural complexity with a single step, in addition to economy of atoms ${ }^{1}$ and selectivity that is an important feature in modern synthetic methodology. ${ }^{2}$

Quinolines and their derivatives are important not only as key structural units in many natural products but also as an important starting material for the chemical and pharmaceutical industry, ${ }^{3}$ for example it act as anti-inflammatory, ${ }^{4}$ anticancer, ${ }^{5}$ antituberculosis, ${ }^{6}$ etc.<smiles>[R][X]c1ccc(-c2cc(-c3ccccc3)c3cc([N+](=O)[O-])ccc3n2)cc1</smiles>

Figure 1. 6-nitro-2,4-diphenylquinoline derivatives.

In this work we report a method to synthetize quinolines derivatives in the MCR using $p$ nitroaniline (1), benzaldehyde derivatives (2a-i), phenylacetylene (3), and niobium pentachloride as reaction promoter.

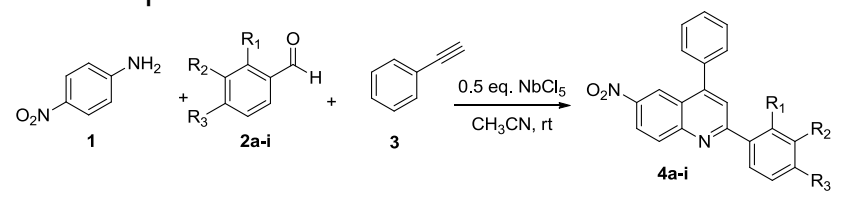

Scheme 1: MCR using $\mathrm{NbCl}_{5}$ as promoter.

\section{RESULTS AND DISCUSSION}

The MCRs were realized at room temperature an air atmosphere, with constant agitation and using $\mathrm{CH}_{3} \mathrm{CN}$ anhydrous as solvent. The $\mathrm{NbCl}_{5}$ were used in a proportion of $50 \mathrm{~mol} \%$ for each benzaldehyde derivatives used in the reactions. The reaction was complete within 96 hours, the products were formed in good to high yields (75-98\%) and characterized through spectrometric and spectroscopic methods.

The results obtained are descried in the table 1. Table 1. Results obtained at MCR promoted by $\mathrm{NbCl}_{5}$.

\begin{tabular}{|c|c|c|c|c|}
\hline Benzaldehyde & $\mathbf{R}_{\mathbf{1}}$ & $\mathbf{R}_{\mathbf{2}}$ & $\mathbf{R}_{\mathbf{3}}$ & Yield (\%) \\
\hline $\mathbf{2 a}$ & $\mathrm{F}$ & $\mathrm{H}$ & $\mathrm{H}$ & 87 \\
\hline $\mathbf{2 b}$ & $\mathrm{Cl}$ & $\mathrm{H}$ & $\mathrm{H}$ & 92 \\
\hline $\mathbf{2 c}$ & $\mathrm{Br}$ & $\mathrm{H}$ & $\mathrm{H}$ & 81 \\
\hline $\mathbf{2 e}$ & $\mathrm{H}$ & $\mathrm{F}$ & $\mathrm{H}$ & 75 \\
\hline $\mathbf{2 d}$ & $\mathrm{H}$ & $\mathrm{Cl}$ & $\mathrm{H}$ & 98 \\
\hline $\mathbf{2} \mathbf{f}$ & $\mathrm{H}$ & $\mathrm{Br}$ & $\mathrm{H}$ & 79 \\
\hline $\mathbf{2 g}$ & $\mathrm{H}$ & $\mathrm{H}$ & $\mathrm{F}$ & 98 \\
\hline $\mathbf{2} \mathbf{h}$ & $\mathrm{H}$ & $\mathrm{H}$ & $\mathrm{Cl}$ & 86 \\
\hline $\mathbf{2 i}$ & $\mathrm{H}$ & $\mathrm{H}$ & $\mathrm{Br}$ & 98 \\
\hline
\end{tabular}

Analyzing the data above, we can verify that the MCR promoted by $\mathrm{NbCl}_{5}$ to synthesis quinolines derivatives show good to high yield and good reaction time.

\section{CONCLUSION}

In conclusion, this work shows that the $\mathrm{NbCl}_{5}$ is a good promoter to act as Lewis Acid in MCR between benzaldehyde derivatives, $p$ nitroaniline and phenylacetylene, obtaining the products with good to high yields.

\section{ACKNOWLEDGEMENTS}

The authors thank the FAPESP, CAPES and CNPQ for financial support and CBMM for $\mathrm{NbCl}_{5}$. \footnotetext{
REFERENCES

${ }^{1}$ Bienaymé, H.; Hulme, C.; Oddon, G.; Schimitt, P. Chem. Eur. J. 2000, 6, 3321.

Isambert, N.; Lavilla, R. Chem. Eur. J. 2008, 14, 8444

Sawada Y.; Kayakiri H. ; Abe Y. ; Imai K. ; Katayama A. ; Oku T. ; Tanaka H. ; Med Chem. J. 2004, 47, 1617.

4 Pellerano, C.; Savini, L.; Massarelli, P.; Bruni, G.; Fiaschi, A. I. Farmaco 1990, 45, 269.

5 Joseph, B.; Darro, F.; Behard, A.; Lesur, B.; Collignon, F.; Decaestecker,

C.; Frydman, A.; Guillaumet, G.; Kiss, R. J. Med. Chem. 2002, 45, 2543.

Upadhayaya, R. S.; Vandavasi, J. K.; Vasireddy, N. R.; Sharma, V.; Dixit,

S. S.; Chattopadhyaya, J. Bioorg. Med. Chem. 2009, 17, 2830.

7 Lacerda, Jr. V.; Santos D. A.; Silva-filho, L. C.; Greco, S. J.; Santos, R.

B. Aldrichimica Acta. 2012, 45, 19.
} 